\title{
Evapotranspiração real diária em sub-bacias do Paracatu, utilizando produtos do sensor Modis ${ }^{1}$
}

\author{
Evaldo de Paiva Lima², Gilberto Chohaku Sediyama ${ }^{3}$ Ricardo Guimarães Andrade, \\ Vinícius Duarte Lopes ${ }^{5}$, Bernardo Barbosa da Silva
}

\section{RESUMO}

A evapotranspiração define a perda total de água do sistema solo-planta para a atmosfera. Nas áreas agrícolas, particularmente onde se pratica algum tipo de irrigação, a determinação da evapotranspiração, por via de sensoriamento remoto, vem ganhando cada vez mais importância, pois possibilita identificar a eficiência com que a água tem sido utilizada. Nesse contexto, este trabalho tem o objetivo de determinar a evapotranspiração real diária $\left(\mathrm{ETr}_{\text {diária }}\right)$, com a utilização de produtos do sensor MODIS, nas sub-bacias do Ribeirão Entre Ribeiros e Rio Preto, que ficam entre os Estados de Goiás e Minas Gerais. O SEBAL (Surface Energy Balance Algorithm for Land) foi utilizado para a obtenção da $\operatorname{ETr}_{\text {díria }}$ em quatro dias diferentes, no período de julho a outubro de 2007. Os resultados encontrados foram compatíveis com os citados em outras literaturas e a comparação entre a evapotranspiração, obtida pelo SEBAL, e a evapotranspiração da cultura (ETc) demonstraram que esse algoritmo pode ser utilizado como boa opção para determinar, com a utilização de produtos do sensor MODIS, a evapotranspiração diária nas condições das sub-bacias do ribeirão Entre Ribeiros e rio Preto.

Palavras-chave: fluxo de calor no solo, fluxo de calor sensível, bacias hidrográficas, sensoriamento remoto.

\section{ABSTRACT}

\section{Daily actual evapotranspiration in sub-basins of Paracatu using Modis sensor products}

Evapotranspiration defines the total loss of water from the soil-plant system to the atmosphere. In agricultural areas, particularly under some form of irrigation, the remote sensing-based determination of evapotranspiration is gaining increasing importance, since it provides a measure of water use efficiency. In this context, this study aimed to estimate the daily actual evapotranspiration (ETr) using MODIS sensor products in the sub-basins of Entre Ribeiros creek and Preto river, between the states of Goiás and Minas Gerais. The Surface Energy Balance Algorithm for Land (SEBAL) was used to obtain the ETr in four different days from July to October, 2007. The results were consistent with other reports in the literature and the comparison between the evapotranspiration by SEBAL and crop evapotranspiration (ETc) showed that this algorithm can be a good option to estimate the daily evapotranspiration using MODIS sensor products in the conditions of the sub-basins of Entre Ribeiros creek and Preto river.

Key words: soil heat flux, sensible heat flux, river basins, remote sensing.

\footnotetext{
Recebido para publicação em 19/02/2013 e aprovado em 01/08/2013.

${ }^{1}$ Este trabalho é parte da tese de doutorado do primeiro autor. Fonte Financiadora: CAPES e CNPq

${ }^{2}$ Meteorologista, Doutor. Embrapa - Centro Nacional de Pesquisa de Solos, Rua Jardim Botânico, 1024, Jardim Botânico, 22460-000, Rio de Janeiro, Rio de Janeiro, Brasil. evaldo.lima@embrapa.br (autor para correspondência).

${ }^{3}$ Engenheiro-Agrônomo, Ph.D. Departamento de Engenharia Agrícola, Universidade Federal de Viçosa, Campus Viçosa, Avenida Peter Henry Rolfs, s/n, 36570-000, Viçosa, Minas Gerais, Brasil. g.sediyama@ufv.br

${ }^{4}$ Engenheiro Agrícola, Doutor. Embrapa - Centro Nacional de Pesquisa por Monitoramento, Avenida Soldado Passarinho, 303, Fazenda Chapadão, 13070-115, Campinas, São Paulo, Brasil. ricardo.andrade@embrapa.br

${ }^{5}$ Bacharel em Ciência da Computação. Departamento de Informática, Universidade Federal de Viçosa, Campus Viçosa, Avenida Peter Henry Rolfs, s/n, 36570-000, Viçosa, Minas Gerais, Brasil.vin.duartelopes@gmail.com

${ }^{6}$ Meteorologista, Doutor. Departamento de Ciências Geográficas, Universidade Federal de Pernambuco, Avenida Acadêmico Hélio Ramos, s/n, Cidade Universitária, 50741-530, Recife, Pernambuco, Brasil. bbdasilva.ufpe@gmail.com
} 


\section{INTRODUÇÃO}

A estimativa da evapotranspiração é essencial em sistemas de irrigação, em cálculos de perdas de água em reservatórios e do balanço hídrico, nas modelagens hidrológicas, tanto em abordagens distribuídas, quanto em concentradas, e nas modelagens climáticas. O manejo da água de irrigação é muito importante em locais onde a produção agrícola irrigada representa grande percentagem da economia regional. A estimativa mais acurada da demanda de água pelas culturas e a programação dos intervalos de irrigação promovem maior eficiência no uso dos recursos hídricos (Medina et al., 1998).

Rollenbeck \& Anhuf (2007) citaram que a principal chave que liga hidrologia e meteorologia é a evapotranspiração, uma vez que esta contribui, de maneira expressiva, na partição do balanço de energia à superfície e no balanço hídrico regional que, por sua vez, contribuem para a definição das condições climáticas locais e do prognóstico do escoamento superficial.

Para Bastiaanssen (2000), a agricultura irrigada é o maior consumidor de água em bacias hidrográficas. Os impactos dessa atividade também poderiam ser avaliados por meio de modelos hidrológicos, inclusive os que propõem interação com a atmosfera, uma vez que procuram explicar os processos do ciclo hidrológico, mas, em geral, esses modelos requerem alto número de medições de campo, para que suas calibrações sejam realizadas de maneira satisfatória (Hemakumara et al., 2003).

Em razão disso, o uso dos dados de sensoriamento remoto vem-se tornando ferramenta potencial para a determinação de fluxos de superfície e da evapotranspiração. Além das dificuldades de obtenção da evapotranspiração que, na maioria das vezes, está relacionada com a escassez de dados necessários para a implementação de alguns dos métodos, outro fator importante a ser considerado é a distribuição espacial da evapotranspiração.

Os métodos de estimativa da evapotranspiração, em geral, permitem a sua obtenção em escala local. No entanto, regiões marcadas por heterogeneidade da superfície, como tipos de solo e de vegetação, apresentam taxas de evapotranspiração bastante diferentes, que podem não ser percebidas nas formas tradicionais de estimativas. Diferentemente disso, o sensoriamento remoto permite a estimativa da evapotranspiração em grandes áreas, como função das características biofísicas encontradas em cada pixel. Outra grande vantagem do emprego de imagens de satélites na estimativa da evapotranspiração, em escala regional, reside no fato de que a quantidade de água consumida no processo de evapotranspiração pode ser obtida diretamente, sem a necessidade de se quantificarem outros parâmetros hidrológicos, como a umidade do solo.
A aplicação de técnicas de sensoriamento remoto permite a determinação espacial da evapotranspiração, ou seja, a energia necessária para esse processo pode ser obtida como um termo residual do balanço de energia à superfície. $\mathrm{O}$ balanço de energia descreve as interações físicas entre a superfície e a atmosfera. Resolver a equação do balanço de energia envolve a subdivisão da energia líquida disponível em fluxos utilizados em diferentes processos na superfície terrestre, como fluxo de calor latente, fluxo de calor sensível e fluxo de calor no solo (Timmermans \& Meijerink, 1999).

O SEBAL (Surface Energy Balance Algorithm for Land) é um algoritmo que possibilita a estimativa dos fluxos de energia que ocorrem na interface solo-vegetaçãoatmosfera, com os dados obtidos por meio de sensoriamento remoto. Esse algoritmo estima o fluxo de calor latente como resíduo da equação clássica do balanço de energia. No entanto, o saldo de radiação, o fluxo de calor no solo e o fluxo de calor sensível precisam ser estimados.

Esse algoritmo tem sido utilizado em diversos lugares do mundo, de diferentes condições climáticas, com resultados promissores. No Brasil, já existem estudos envolvendo a aplicação dessa ferramenta (Mendonça, 2007; Andrade, 2008; Nicácio, 2008; Lima, 2010; Ruhoff, 2011 e Oliveira, 2012), que foram realizados para diferentes localidades. Em razão disso, este trabalho objetivou estimar a evapotranspiração real diária, com a utilização de produtos do sensor MODIS (Moderate Resolution Imaging Spectrometer), a bordo do satélite Terra, nas sub-bacias do ribeirão Entre Ribeiros e rio Preto.

\section{MATERIAL E MÉTODOS}

\section{Área de estudo}

A bacia do rio Paracatu é uma importante sub-bacia do rio São Francisco. Localizada no Médio São Francisco drena uma área de aproximadamente $45.600 \mathrm{~km}^{2}$, que representa cerca de $7 \%$ da área de drenagem da bacia do São Francisco.

O clima da bacia é predominantemente tropical chuvoso, havendo concentração das chuvas no período de outubro a abril, com destaque para o trimestre novembro, dezembro e janeiro como o mais chuvoso. Segundo Brasil (1996) citado por Moreira (2006), a precipitação média anual na bacia é de $1.338 \mathrm{~mm}$, enquanto a evapotranspiração média anual é de $1.140 \mathrm{~mm}$.

As sub-bacias do ribeirão Entre Ribeiros e do rio Preto, localizadas na região do Alto Paracatu, abrangem parte do Distrito Federal e dos Estados de Goiás e Minas Gerais (Figura 1). Segundo Latuf (2007), as subbacias do ribeirão Entre Ribeiros e do rio Preto drenam uma área de aproximadamente $14.149 \mathrm{~km}^{2}$, dos quais $74,87 \%\left(10.621 \mathrm{~km}^{2}\right)$ encontram-se no Estado de Minas 
Gerais, $15,71 \%\left(2.212 \mathrm{~km}^{2}\right)$ no Estado de Goiás e 9,42\% $\left(1.316 \mathrm{~km}^{2}\right)$ no Distrito Federal.

Na bacia do rio Preto, como exemplo, o uso do solo é caracterizado pela pecuária intensiva e a agricultura mecanizada de alta tecnologia, especialmente da utilização intensiva de pivôs centrais no processo de irrigação. Borges (2008), utilizando imagens do sensor LANDSAT/ETM+ do ano de 2003, identificou 226 pivôs na bacia do rio Preto. Destes, 87 estavam localizados no Distrito Federal, $81 \mathrm{em}$ Minas Gerais e 58 em Goiás. Este autor ainda cita que as principais atividades desenvolvidas na bacia são as produções de leite e de grãos, com destaque para as culturas do milho, soja, feijão, sorgo, trigo e hortaliças em geral.

\section{Aquisição e processamento dos dados}

Os produtos do sensor MODIS: MOD09GA (refletância espectral de superfície, bandas 1 a 7), MOD11A1 (temperatura da superfície, bandas 31 e 32) e MOD07 (ângulo zenital), dos dias 14 de julho, 13 de agosto, 16 de setembro e 16 de outubro de 2007, foram obtidos no formato HDF (Hierarchical Data Format) e convertidos para o formato GeoTIFF, com o programa MRT (MODIS Reprojection Tool).

Os dados de velocidade do vento e de radiação de onda curta incidente, dos dias relacionados no estudo, foram obtidos na estação meteorológica automática (A542), localizada no Município de Unaí, MG. A estação meteorológica situa-se nas coordenadas geográficas $16^{\circ} 33^{\prime} 14^{\prime \prime}$ Sul e $46^{\circ} 52^{\prime}$ 55" Oeste, em 631 m de altitude, conforme localização apresentada na Figura 1. Essa estação pertence à rede de automáticas do Instituto Nacional de Meteorologia. As informações coletadas serviram como dados de entrada no SEBAL para estimar a evapotranspiração real diária.
Todas as etapas do processo de estimativa dos componentes do balanço de energia, e consequentemente, da determinação da evapotranspiração real diária para a área em estudo, foram desenvolvidas com a ferramenta Model Maker do programa Erdas 9.1. Para descrição completa dos procedimentos adotados, consulte-se o trabalho de Lima (2010). $\mathrm{O}$ saldo de radiação instantâneo $\left(\mathrm{Rn}_{\text {inst. }}\right)$ foi a primeira componente do balanço de energia a ser obtida. Para tanto, aplicou-se a equação sugerida por Allen et al. (2002):

$R n_{\text {inst. }}=R_{s \downarrow}-\alpha R_{s \downarrow}+R_{L \downarrow}-R_{L \uparrow}-\left(1-\varepsilon_{o}\right) R_{L \downarrow}$

em que $R_{s \downarrow}$ é a radiação de onda curta incidente $\left(\mathrm{W} \cdot \mathrm{m}^{-2}\right), \alpha$ é o albedo da superfície (adimensional), $R_{L \downarrow}$ é a radiação de onda longa emitida pela atmosfera $\left(\mathrm{W} \cdot \mathrm{m}^{-2}\right), R_{L \uparrow}$ é a radiação de onda longa emitida pela superfície $\left(\mathrm{W} \cdot \mathrm{m}^{-2}\right) \mathrm{e}$, $\varepsilon_{\mathrm{o}}$ é a emissividade da superfície (adimensional).

Após a estimativa do $\mathrm{Rn}_{\text {inst. }}$ realizou-se, com a aplicação da equação empírica sugerida por Bastiaanssen (2000), a determinação do fluxo instantâneo de calor no solo $(\mathrm{G})$.

$\mathrm{G}=\left[\frac{\mathrm{T}_{\mathrm{s}}}{\alpha}\left(0,0038 \alpha+0,0074 \alpha^{2}\right)\left(1-0,98 \mathrm{NDVI}^{4}\right)\right] \mathrm{Rn}_{\text {inst. }}$

em que $\mathrm{T}_{\mathrm{s}}$ é a temperatura da superfície $\left({ }^{\circ} \mathrm{C}\right)$ relativa ao produto MOD11A1 e NDVI é o índice de vegetação da diferença normalizada. Para efeito de correção dos valores do fluxo de calor no solo para corpos d'água (NDVI < 0 ), considerou-se G =0,3Rn (Silva \& Bezerra, 2006).

Na sequência, obteve-se o fluxo instantâneo de calor sensível (H). Esta componente do balanço de energia expressa a taxa de calor transferido da superfície para o ar pelos processos de convecção e condução. Este fluxo foi calculado, utilizando-se a velocidade do vento (u), a re-

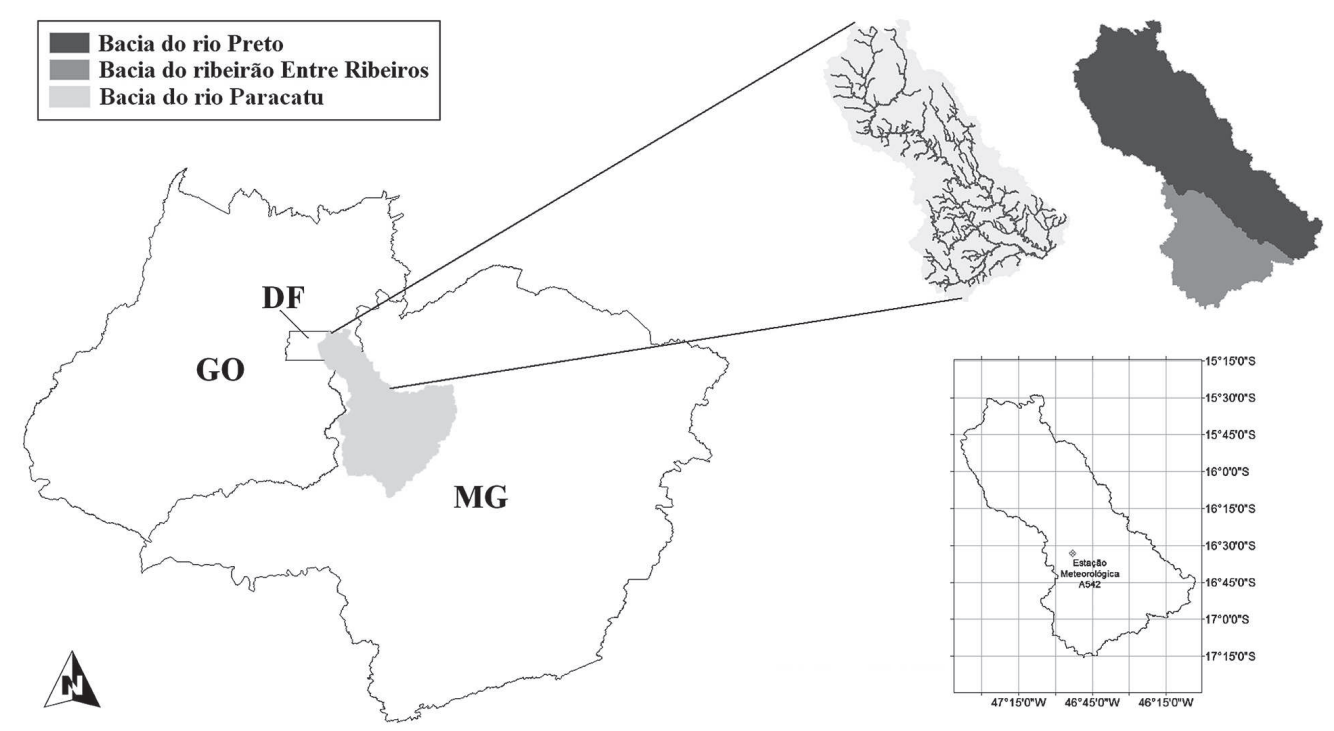

Figura 1. Localização da área de estudo. No primeiro plano, em cinza, está a bacia do Paracatu e no segundo, as sub-bacias em estudo. 
sistência aerodinâmica da superfície $\left(\mathrm{r}_{\mathrm{ah}}\right)$ e a diferença da temperatura do ar (dT) entre dois níveis acima da superfície, ou seja, nas alturas de 2,0 m e 0,1 m. A Figura 2 apresenta o fluxograma das etapas utilizadas na estimativa do fluxo de calor sensível.

No SEBAL, procedeu-se ao cálculo de dT para cada pixel, por meio de uma relação linear entre dT e Ts. Essa relação é dada pelos coeficientes a e b, que são obtidos pelos pixels denominados "âncoras", também chamados de "quente" e "frio". No pixel "frio" a temperatura da superfície e a do ar próximo à superfície foram consideradas iguais. Nesse caso, assumiu-se que o fluxo de calor sensível é igual a zero e, então, determinou-se o fluxo de calor latente máximo. Entretanto, no pixel "quente" assumiu-se o fluxo de calor latente como igual a zero e, então, obteve-se o fluxo de calor sensível máximo. Os pixels "quente" e "frio" foram selecionados ao se consultar simultaneamente os mapas temáticos do NDVI e da temperatura da superfície (Ts). Dessa forma, o pixel "frio" foi escolhido numa situação em que o valor do NDVI era negativo, geralmente sobre corpos d'água, e apresentava um baixo valor da Ts. O pixel "quente" foi selecionado para a condição em que a Ts era elevada e o NDVI entre 0,1 e 0,2, que representa uma área não irrigada e considerada seca.

O fluxo instantâneo de calor latente ( $\lambda \mathrm{ET}), \mathrm{em} \mathrm{W} \cdot \mathrm{m}^{-2}$, foi calculado, como resíduo da equação do balanço de energia, pela simples diferença entre os mapas temáticos do saldo de radiação, fluxo de calor no solo e fluxo de calor sensível.

$\lambda E T=R n_{\text {inst. }}-G-H$
Posteriormente, foi possível calcular a fração evaporativa por meio da expressão sugerida por Bastiaanssen et al. (1998):

$\mathrm{FE}=\frac{\lambda E T}{\lambda E T+H}=\frac{\lambda E T}{R n_{\text {inst }}-G}$

Estudos micrometeorológicos indicam que esse termo pode ser considerado constante durante o período diurno (Ayenew, 2003). Dessa forma, estima-se a evapotranspiração por meio da seguinte expressão:

$E T r_{\text {diária }}=\frac{86400 F E R n_{24 h}}{\lambda}$

em que $\operatorname{ETr}_{\text {díria }}$ é a evapotranspiração real diária $\left(\mathrm{mm} \cdot \mathrm{d}^{-1}\right)$, FE é a fração evaporativa (adimensional), $\mathrm{Rn}_{24 \mathrm{~h}}$ é o saldo de radiação médio, ocorrido em um período de 24 horas $\left(\mathrm{W} \cdot \mathrm{m}^{-2} \cdot \mathrm{d}^{-1}\right)$ e $\lambda$ é o calor latente de vaporização da água $\left(\mathrm{MJ} . \mathrm{kg}^{-1}\right)$.

\section{Comparação entre a evapotranspiração obtida pelo $\mathrm{SEBAL}$ e a no campo}

Para efetuar a comparação da evapotranspiração, obtida por meio do SEBAL (ETr), e a evapotranspiração da cultura (ETc), ao nível diário, foram utilizadas informações da ETc para o feijão, fornecidas pela IRRIGER, que é uma empresa de base tecnológica com prestação de serviço na área de gerenciamento da irrigação. A ETc foi determinada com base no coeficiente de cultura $(\mathrm{Kc})$, relativo à fase de desenvolvimento da cultura, o método de Penman-Monteith, preconizado pela FAO em 1998, e coeficiente de estresse hídrico (Ks).

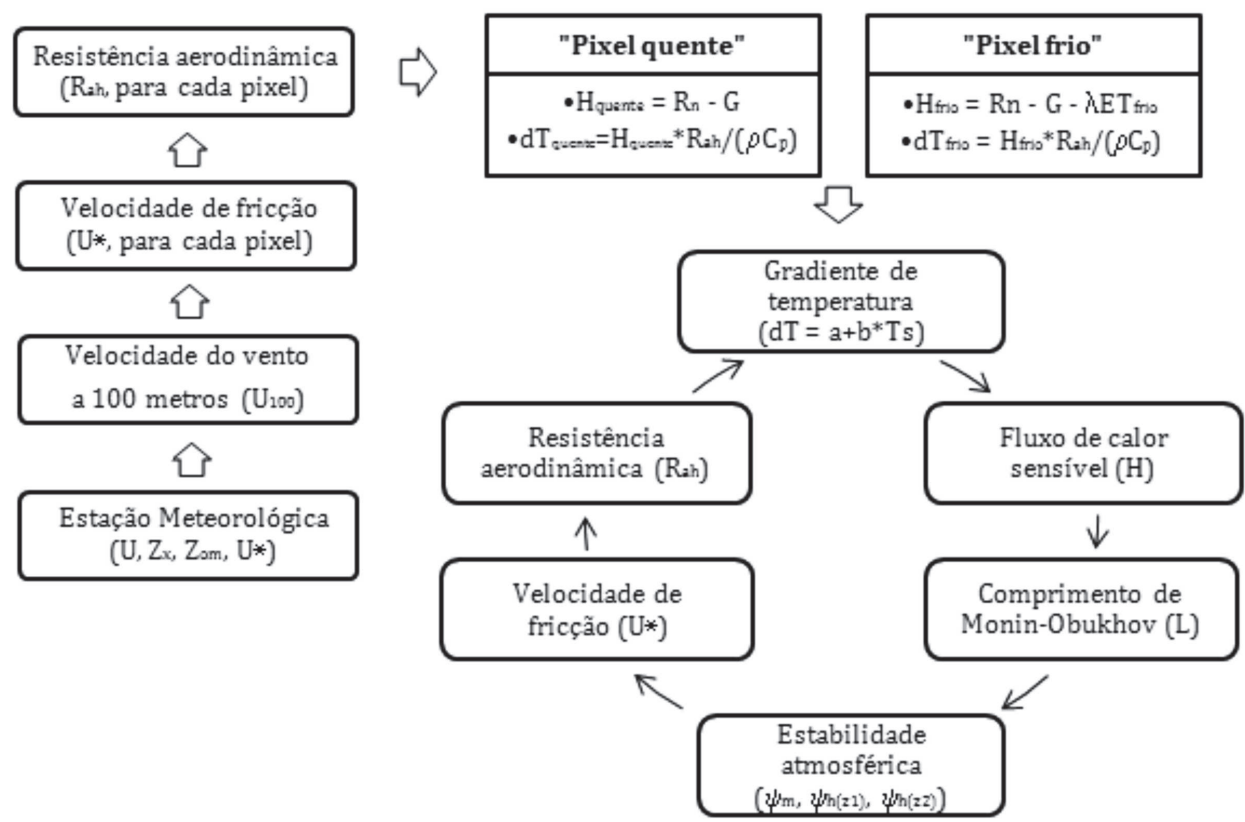

Figura 2. Fluxograma para a estimativa do fluxo instantâneo de calor sensível. 
Utilizaram-se as informações da evapotranspiração da cultura de um dos pivôs centrais da Fazenda Decisão, localizada no Município de Unaí, MG, que faz uso intensivo de pivôs centrais na irrigação de várias culturas. Essa fazenda encontra-se a Oeste da sede do Município em questão e está localizada próxima a área das sub-bacias do ribeirão Entre Ribeiros e do rio Preto.

O pivô utilizado cobria uma área de 120,22 ha, nas coordenadas geográficas, do ponto central, de $16^{\circ} 27^{\prime}$ '31,7" Sul e, $7^{\circ} 18^{\prime}$ 4,7" Oeste, em 979 m de altitude. Nessa área, plantou-se o cultivar de feijão Pérola, que é proveniente do trabalho de seleção de linhas puras da cultivar Aporé - realizado pela Embrapa Arroz e Feijão -, em duas datas distintas. Na primeira metade da área, o feijão foi plantado no dia 8 de maio de 2007 e na segunda, no dia 12 de maio de 2007. Os ciclos finalizaram-se nos dias 18 e 24 de agosto, respectivamente, e apresentaram produtividade de 52 sacas/hectare.

Para realizar a comparação, utilizaram-se datas em que se tinham disponíveis produtos do sensor MODIS, ou seja, 10, 14 e 23 de julho, e 6 e 13 de agosto de 2007. A cultura encontrava-se na Fase III, nos dias 10/07, 14/07, 23/07 e 6/08, e na Fase IV, no dia 13/08. Dessa forma, os valores da evapotranspiração, obtidos por meio do SEBAL, do pixel referente à coordenada do ponto central do pivô, bem como dos oito pixels adjacentes, serviram para verificar, conforme proposta de Oliveira (2012), o comportamento dos erros relativo e absoluto de cada pixel, em comparação com evapotranspiração da cultura do feijão.

\section{RESULTADOS E DISCUSSÃO}

Com a elaboração dos mapas temáticos do albedo da superfície e do saldo de radiação instantâneo $\left(\mathrm{Rn}_{\text {inst. }}\right)$, que podem ser visualizados no trabalho de Lima et al. (2012), juntamente com os mapas de temperatura da superfície e índice de vegetação da diferença normalizada, foram obtidos os mapas temáticos do fluxo de calor no solo (Figura 3), para as sub-bacias do ribeirão Entre Ribeiros e do rio Preto.

A variação espacial do fluxo de calor no solo, observada em cada um dos mapas temáticos, com exceção de pequenas áreas isoladas, foi bastante homogênea. Verifica-se que, nos dois primeiros mapas, a tonalidade predominante foi da classe de valores entre 51 e $100 \mathrm{~W} . \mathrm{m}^{-2}$. Na Figura 3a, observam-se pequenas áreas com a tonalidade amarela $\left(<50 \mathrm{~W} \cdot \mathrm{m}^{-2}\right)$ e azul clara $\left(151\right.$ a $\left.200 \mathrm{~W} \cdot \mathrm{m}^{-2}\right)$, ao passo que, no Alto rio Preto (Figuras $3 b$ ) existem áreas com tonalidade verde (101 a $\left.150 \mathrm{~W} \cdot \mathrm{m}^{-2}\right)$. Entretanto, nas Figuras $3 c$ e $3 d$ observa-se uma predominância da classe de valores entre 101 e $150 \mathrm{~W} \cdot \mathrm{m}^{-2}$ de fluxo de calor no solo (tonalidade verde). $\mathrm{O}$ aumento dos valores do $\mathrm{G}$, verificado nas Figs. 3c e 3d, pode estar relacionado com o aumento do saldo de radiação, que, segundo Sellers (1969), cita- do por Silva \& Bezerra (2006), os percentuais do saldo de radiação para aquecer o solo estão na faixa de 5 a $12 \%$.

Apesar dessa relação de dependência entre o fluxo de calor no solo e o saldo de radiação disponível à superfície, não se pode esquecer que o índice de vegetação da diferença normalizada, a temperatura e o albedo da superfície também foram utilizados para determinar o G. Conforme observa-se na Tabela 1, o fluxo de calor no solo médio variou entre 71,26 $\pm 5,91$ e 134,06 $\pm 6,57 \mathrm{~W} \cdot \mathrm{m}^{-2}$, com valor mínimo de 26,81 W.m-2, no dia 14 de julho e máximo de 223,34 W.m² , no dia 16 de setembro de 2007.

Mendonça (2007) estimou o fluxo de calor no solo instantâneo para a região norte Fluminense, RJ, utilizando imagens do sensor MODIS, e encontrou valores entre 30,49 e $86,77 \mathrm{~W} \cdot \mathrm{m}^{-2}$, com média de $68,97 \mathrm{~W} \cdot \mathrm{m}^{-2}$, no dia 29 de agosto de 2005, 10,00 e 126,65 W.m², com média de 96,51 W.m ${ }^{-2}$, no dia 16 de novembro de 2005, 10,00 e 121,95 W.m², com média de 94,21 W.m² ${ }^{-2}$, no dia 05 de fevereiro de 2006, e 10,00 e 46,72 W.m², com média de $36,99 \mathrm{~W} \cdot \mathrm{m}^{-2}$, no dia 15 de junho de 2006.

Os resultados obtidos por Mendonça (2007) serviram para verificar os resultados do fluxo de calor no solo, encontrados para as duas sub-bacias do rio Paracatu, visto que a estação meteorológica automática (A542), do Município de Unaí, MG, não dispunha de informações do G. É importante destacar que os valores mínimos encontrados por Mendonça (2007) foram de 10,00 W.m-2 , e que, pela análise desses resultados, chega-se à conclusão de que esse autor estabeleceu uma condição, no momento do processamento por meio do SEBAL, para que o valor mínimo do fluxo de calor no solo não fosse inferior a $10,00 \mathrm{~W} . \mathrm{m}^{-2}$. De forma geral, os valores do fluxo de calor no solo para as sub-bacias do ribeirão Entre Ribeiros e do rio Preto situaram-se acima dos encontrados por Mendonça (2007). Como exemplo, o valor máximo do $\mathrm{G}$ encontrado por este autor foi de $126,65 \mathrm{~W} . \mathrm{m}^{-2}$, no dia 16/11/05, enquanto o encontrado para as sub-bacias do Paracatu foi de 223,34 W.m-2 no dia 16/ 09/07. Porém, destaca-se que a cobertura do solo, as datas e o horário de imageamento da superfície pelo satélite foram diferentes para as duas áreas de estudo, e isso pode explicar as diferenças.

Na Figura 4, apresentam-se os mapas temáticos dos valores instantâneos do fluxo de calor sensível para as sub-bacias do ribeirão Entre Ribeiros e do rio Preto. Todos os mapas foram marcados pela grande variabilidade espacial do fluxo de calor sensível. Na Figura 4a, observase que grande parte da área de estudo foi dominada pela tonalidade amarela (0 a 200 W.m-2). Nas Figuras 4a e 4b, verificam-se áreas de cor cinza, circuladas por preto, com valores do fluxo de calor sensível negativo. Silva \& Bezerra (2006) explicam que os pixels com $\mathrm{H}$ negativo correspondem aos pixels cuja temperatura da superfície é inferior à temperatura do pixel "frio". 
Valores elevados do fluxo de calor sensível, acima de 401 W.m² ${ }^{-2}$ ocorreram em muitas áreas no Alto rio Preto (Figura 4d), indicando baixa umidade na superfície do solo. Isso significa que, com a baixa umidade, a maior parte da energia
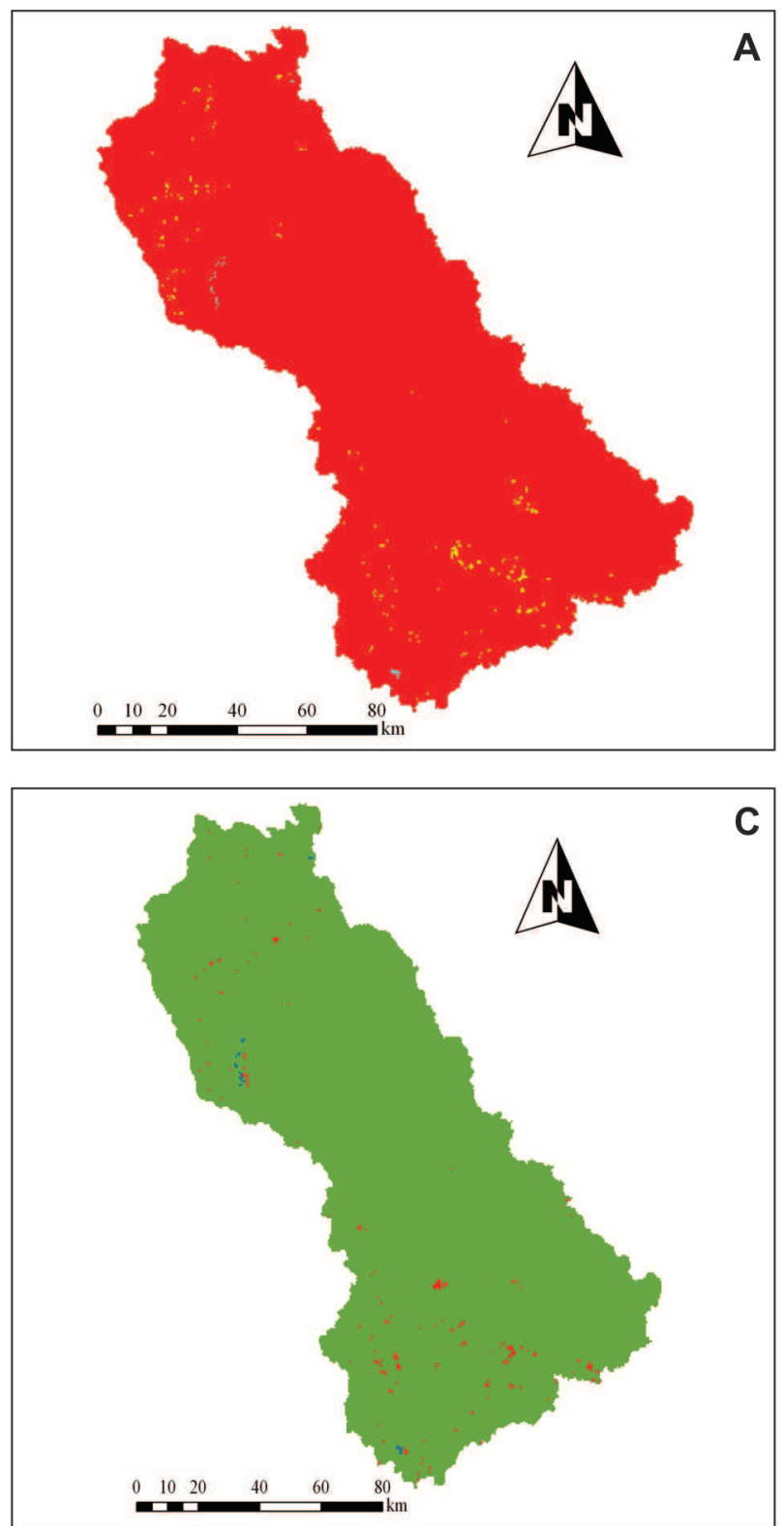

$<\mathbf{5 0}$
A

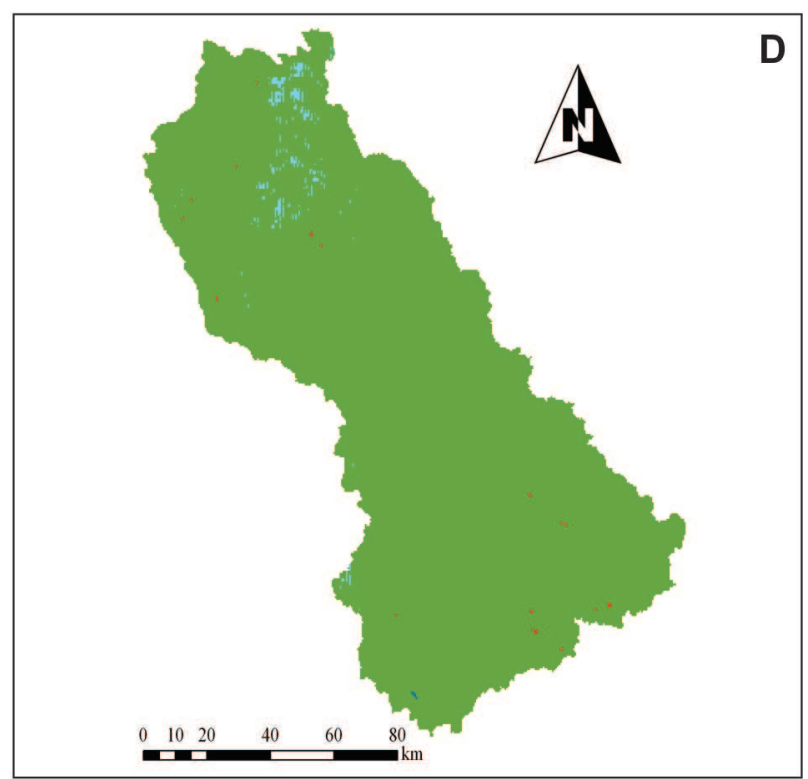

$151-200$

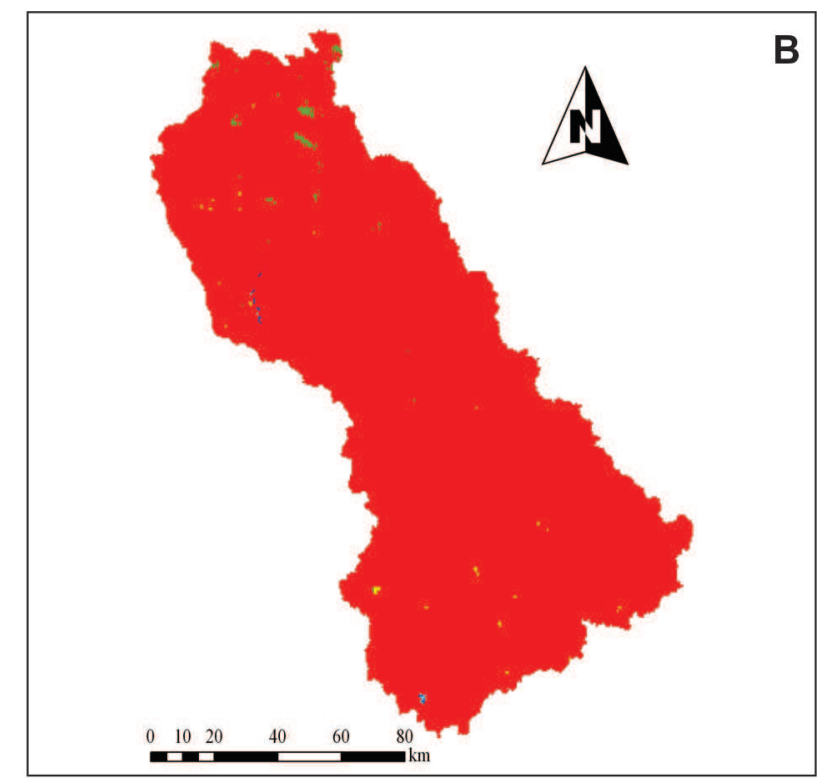

disponível à superfície foi utilizada para aquecer o ar e, o restante, o solo. O fluxo instantâneo de calor sensível médio variou entre 61,70 $\pm 56,48 \mathrm{~W} . \mathrm{m}^{-2}$ e 263,38 $\pm 87,06 \mathrm{~W} . \mathrm{m}^{-2}$, com valores mínimo e máximo de -88,88 W.m² e 720,36 W.m²,

D

Figura 3. Fluxo de calor no solo (W.m-2) para os dias 14 de julho (A), 13 de agosto (B), 16 de setembro (C) e 16 de outubro (D) de 2007.

Tabela 1. Valores mínimos, médios, máximos e desvio padrão (DP) dos fluxos instantâneos de calor no solo (G) e sensível (H), e da evapotranspiração real diária $\left(\mathrm{ETr}_{\text {diária }}\right)$ observadas nos mapas temáticos

\begin{tabular}{|c|c|c|c|c|c|c|c|c|c|c|c|c|}
\hline \multirow{2}{*}{ Datas } & \multicolumn{3}{|c|}{$\mathbf{G}\left(\mathbf{W} \cdot \mathbf{m}^{-2}\right)$} & \multirow[b]{2}{*}{ DP } & \multicolumn{3}{|c|}{$\mathbf{H}\left(\mathbf{W} \cdot \mathbf{m}^{-2}\right)$} & \multirow[b]{2}{*}{ DP } & \multicolumn{3}{|c|}{$\mathbf{E T r} r_{\text {diária }}\left(\mathbf{m m} \mathbf{d}^{-1}\right)$} & \multirow[b]{2}{*}{ DP } \\
\hline & Mín. & Méd. & Máx. & & Mín. & Méd. & Máx. & & Mín. & Méd. & Máx. & \\
\hline $14 / 07$ & 26,81 & 71,26 & 185,28 & 5,91 & $-17,64$ & 61,70 & 519,97 & 56,48 & 0,00 & 2,90 & 4,40 & 0,55 \\
\hline $13 / 08$ & 33,63 & 88,09 & 211,86 & 6,27 & $-88,88$ & 153,77 & 720,36 & 86,18 & 0,00 & 2,97 & 5,54 & 0,86 \\
\hline $16 / 09$ & 55,63 & 118,13 & 223,34 & 5,67 & $-0,81$ & 166,57 & 440,70 & 50,73 & 0,00 & 2,99 & 6,12 & 0,74 \\
\hline $16 / 10$ & 66,42 & 134,06 & 222,07 & 6,57 & $-1,04$ & 263,38 & 694,27 & 87,06 & 0,00 & 2,82 & 6,92 & 1,16 \\
\hline Méd. & 45,62 & 102,89 & 210,64 & 6,11 & $-27,09$ & 161,36 & 593,83 & 70,11 & 0,00 & 2,92 & 5,75 & 0,83 \\
\hline
\end{tabular}

Rev. Ceres, Viçosa, v. 61, n.1, p. 017-027, jan/fev, 2014 
respectivamente, no dia 13 de agosto de 2007, conforme observa-se na Tabela 1.

Mendonça (2007) estimou o fluxo de calor sensível instantâneo para a região norte Fluminense, RJ, utilizando imagens do sensor MODIS, e encontrou valores entre 0,00 e $480,64 \mathrm{~W} \cdot \mathrm{m}^{-2}$, com média de $228,25 \mathrm{~W} \cdot \mathrm{m}^{-2}$, no dia 29 de agosto de 2005; 0,00 e 611,35 W.m² , com média de 285,67 W.m² dia 16 de novembro de $2005 ; 0,00$ e 615,40 W.m-2 , com média de 266,78 W.m ${ }^{-2}$, no dia 05 de fevereiro de 2006, e 0,00 e 291,74 W.m² , com média de 125,42 W.m ${ }^{-2}$, no dia 15 de junho de 2006, com a proposição "clássica", sendo esta a que utiliza a fração evaporativa (FE) na estimativa da evapotranspiração diária.
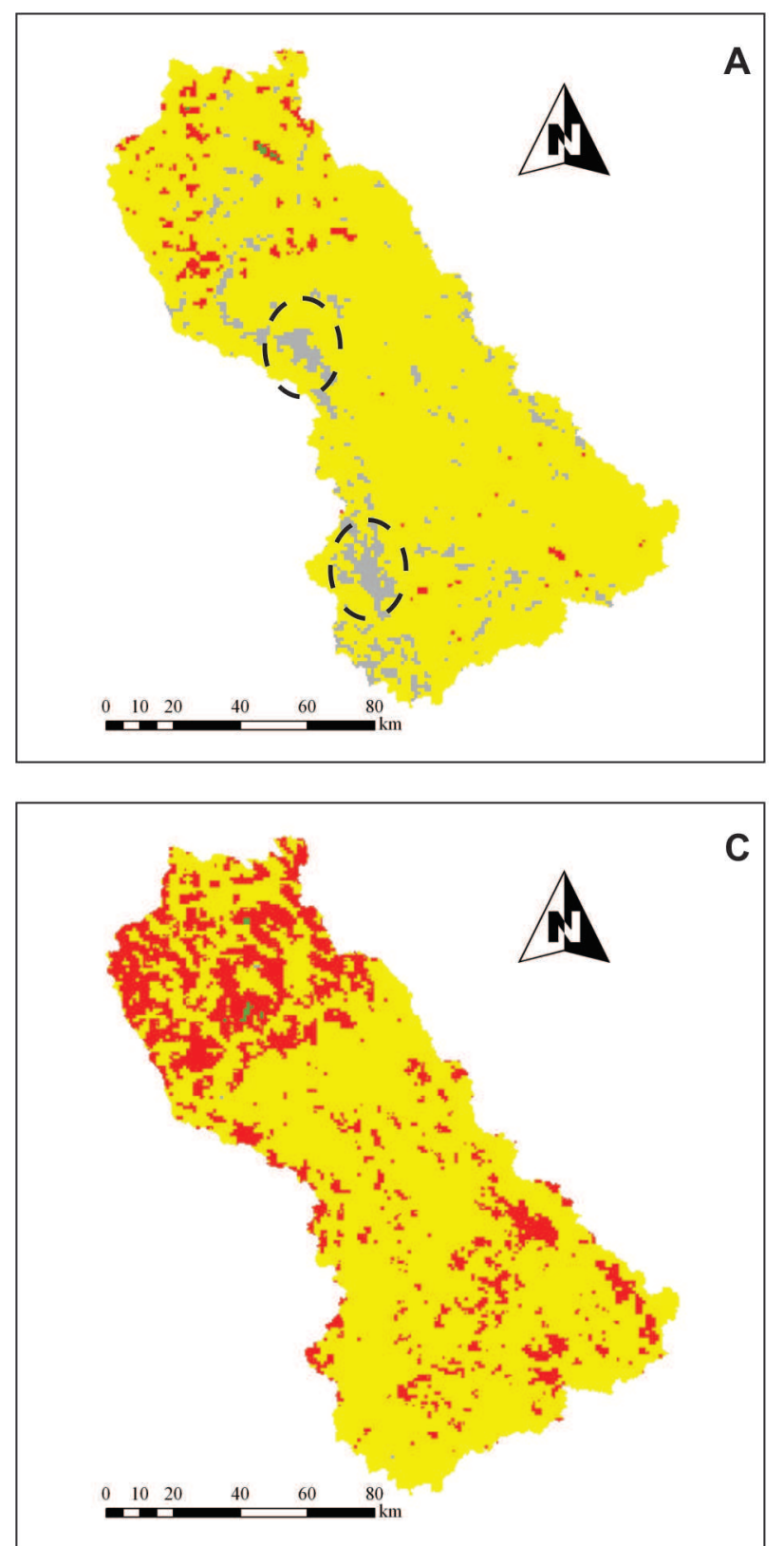

$<0$ 0 - 200 $201-400$

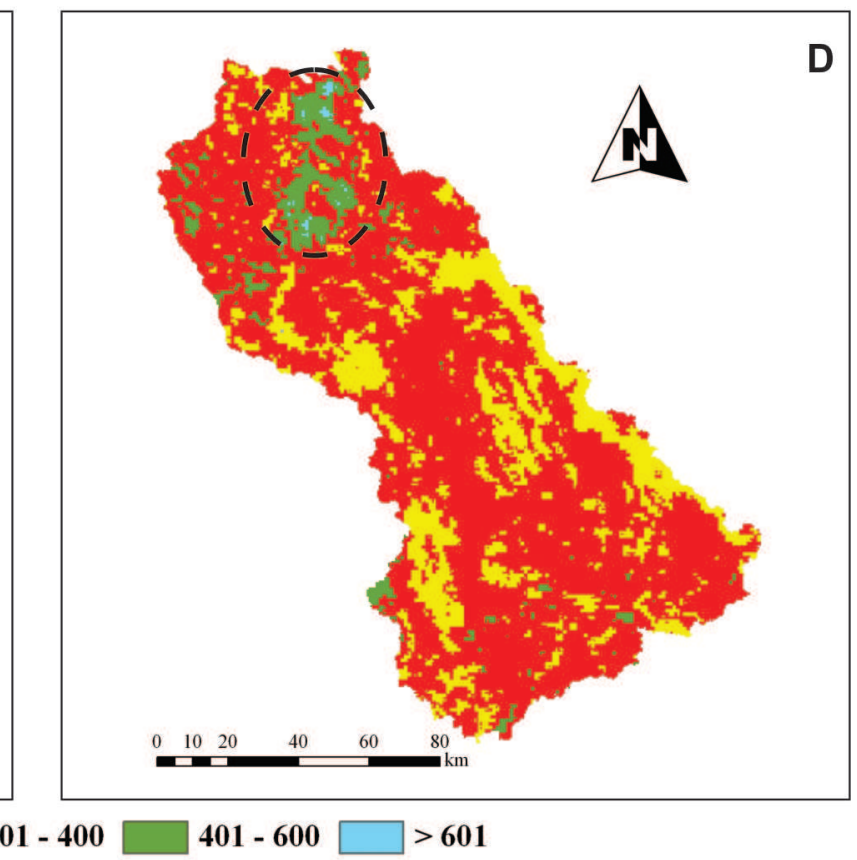

Figura 4. Fluxo de calor sensível (W.m²) para os dias 14 de julho (A), 13 de agosto (B), 16 de setembro (C) e 16 de outubro (D) de 2007.
Nicácio (2008) estimou o fluxo de calor sensível, no dia 12 de outubro de 2004, na região de Petrolina/ Juazeiro, com a utilização de produtos do sensor MODIS, a bordo do satélite Aqua, e observou valores mínimos $(\mathrm{H}<0)$ sobre o leito do rio São Francisco, enquanto os maiores valores do fluxo de calor sensível foram encontrados, especialmente, em região de solo aberto e áreas urbanizadas $\left(>754,4 \mathrm{~W} \cdot \mathrm{m}^{-2}\right)$. Em áreas de savana estépica aberta, os valores encontrados, mais predominantemente, estão na faixa de aproximadamente $535,0 \mathrm{~W} \cdot \mathrm{m}^{-2}$ a $754,0 \mathrm{~W} \cdot \mathrm{m}^{-2}$. Entretanto, em região de savana estépica densa foi possível encontrar valores do $\mathrm{H}$ entre 120,0 e 535,0 W.m ${ }^{-2}$.

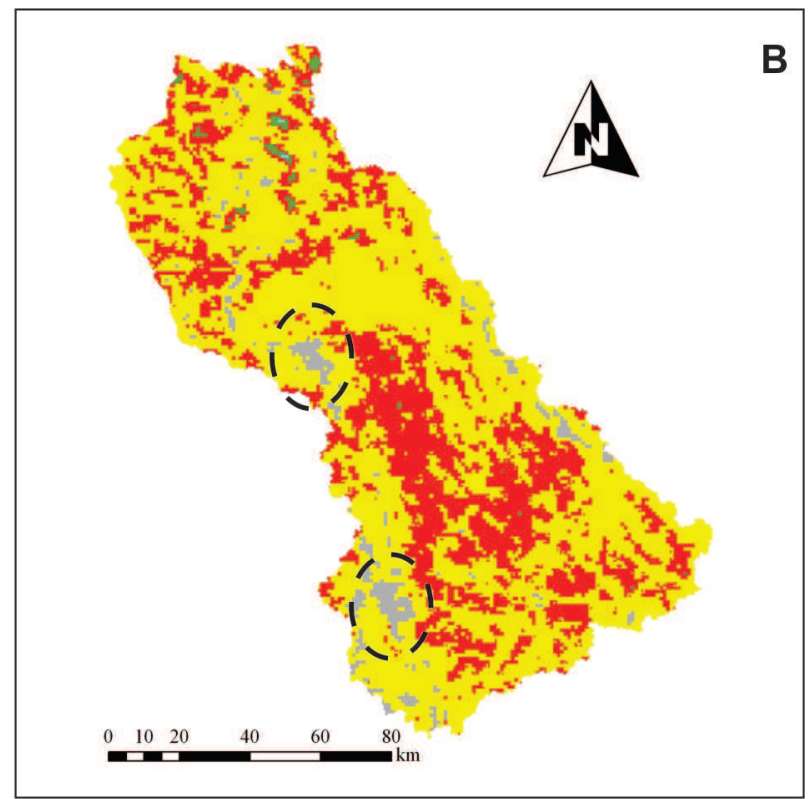


Os resultados do fluxo de calor sensível instantâneo, encontrados por Mendonça (2007) e Nicácio (2008), foram comparados com os resultados obtidos neste estudo. $\mathrm{O}$ valor máximo do $\mathrm{H}$ encontrado nas sub-bacias do ribeirão Entre Ribeiros e do rio Preto foi de 720,36 W.m-2 . Esse resultado foi compatível com o valor máximo encontrado por Nicácio (2008), que, no dia 12 de outubro de 2004, encontrou valor do $\mathrm{H}$ superior a $754,4 \mathrm{~W} \cdot \mathrm{m}^{-2}$. No caso dos valores mínimos, tanto este estudo como o de Nicácio (2008) encontraram valores negativos $(H<0)$. Entretanto, no estudo de Mendonça (2007) não foram verificados valores negativos do fluxo de calor sensível.

Na Figura 5, são apresentados os mapas temáticos dos valores diários da evapotranspiração real $\left(\mathrm{ETr}_{\text {diaria }}\right)$, que foram determinados com base na fração evaporativa e no saldo de radiação médio, ocorrido num período de 24 horas. Da mesma forma que nos mapas do fluxo de calor sensível, observa-se que os de $\mathrm{ETr}_{\text {díria }}$ foram marcados pela grande variabilidade espacial. Nota-se, também, uma relação entre os baixos valores da $\mathrm{ETr}_{\text {diaraia }}$, entre 0,0 e 2,0 mm.d ${ }^{-2}$ na área circulada da Figura $5 d$, e os elevados valores do fluxo de calor sensível, > 401,00 W. $\mathrm{m}^{-2}$, na área circulada da Figura 4d. Por causa da baixa umidade do solo, a evapotranspiração é menor, indicando que, a maior parte da energia disponível foi utilizada para aquecer o ar.

Nos mapas temáticos, a $E \operatorname{Tr}_{\text {díríia }}$ predominou entre 2,1 e 4,0 mm.d $\mathrm{d}^{-1}$ (tonalidade vermelha). A evapotranspiração
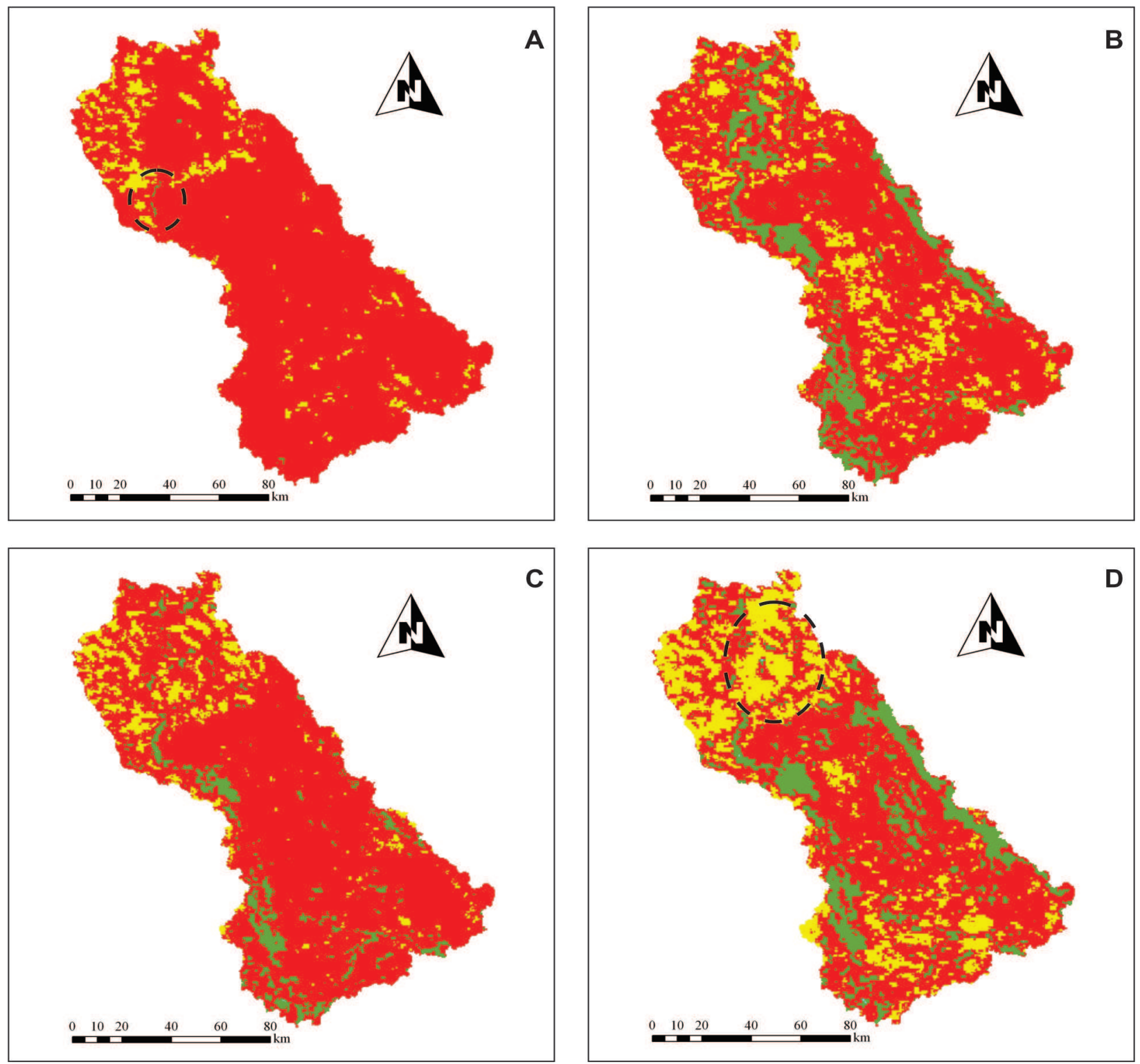

0,0 - 2,0

$2,1-4,0$

$4,1-6,0 \square>6,1$

Figura 5. Evapotranspiração real diária $\left(\mathrm{mm}^{\mathrm{d}} \mathrm{d}^{-1}\right)$ para os dias 14 de julho (A), 13 de agosto (B), 16 de setembro (C) e 16 de outubro (D) de 2007.

Rev. Ceres, Viçosa, v. 61, n.1, p. 017-027, jan/fev, 2014 
real diária foi elevada sobre superfícies líquidas, quando comparada com a de outras áreas. Para exemplificar, observa-se parte da área do rio Preto, circulada na Figura 5a, com valores da $\mathrm{ETr}_{\text {diária }}$ entre 4,1 e 6,0 mm.d $\mathrm{d}^{-1}$. Porém, vale lembrar que, sobre superfícies líquidas, o processo predominante é a evaporação.

A evapotranspiração real diária média variou entre $2,82 \pm 1,16$ e 2,99 $\pm 0,74 \mathrm{~mm} \cdot \mathrm{d}^{-1}$, com valores mínimo de zero e máximo de $6,92 \mathrm{~mm} \cdot \mathrm{d}^{-1}$, no dia 16 de outubro de 2007 , conforme observa-se na Tabela 1 . Na determinação da beleceu-se o critério de desconsiderar valores menores que $0,0 \mathrm{~mm} \cdot \mathrm{d}^{-1}$, por isso todos os valores mínimos encontrados neste estudo foram iguais a zero.
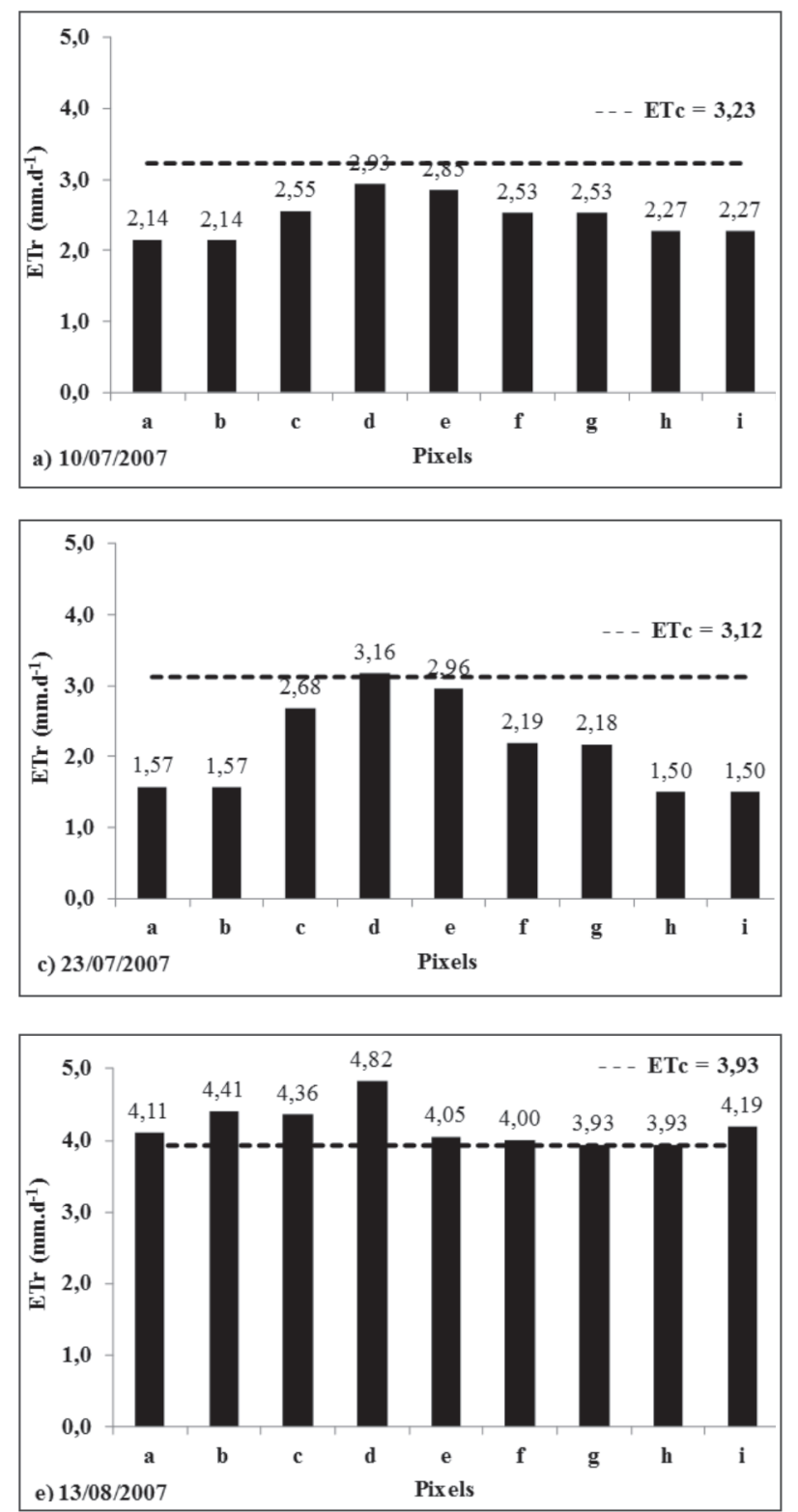
evapotranspiração real diária, por meio do SEBAL, esta-

Mendonça (2007) estimou a evapotranspiração real diária para a região norte Fluminense, RJ, utilizando imagens do sensor MODIS, e encontrou valores entre 0,00 e $7,39 \mathrm{~mm} \cdot \mathrm{d}^{-1}$, com média de $3,25 \mathrm{~mm} \cdot \mathrm{d}^{-1}$, no dia 29 de agosto de 2005, 0,00 e 10,65 mm.d $\mathrm{d}^{-1}$, com média de 4,50 mm.d ${ }^{-1}$, no dia 16 de novembro de 2005, 0,00 e 10,12 mm.d ${ }^{-1}$, com média de 4,65 mm.d $\mathrm{d}^{-1}$, no dia 05 de fevereiro de 2006, e 0,00 e $5,45 \mathrm{~mm} \cdot \mathrm{d}^{-1}$, com média de $2,73 \mathrm{~mm} \cdot \mathrm{d}^{-1}$, no dia 15 de junho de 2006. Esses resultados referem-se à proposição chamada "clássica", e que utiliza o saldo de radiação médio ocorrido em um período de 24 horas $\left(\mathrm{Rn}_{24 \mathrm{~h}}\right)$.

A variação da evapotranspiração, encontrada por Mendonça (2007) no dia 15 de junho de 2006, foi compatível com a encontrada no dia 13 de agosto de 2007, para
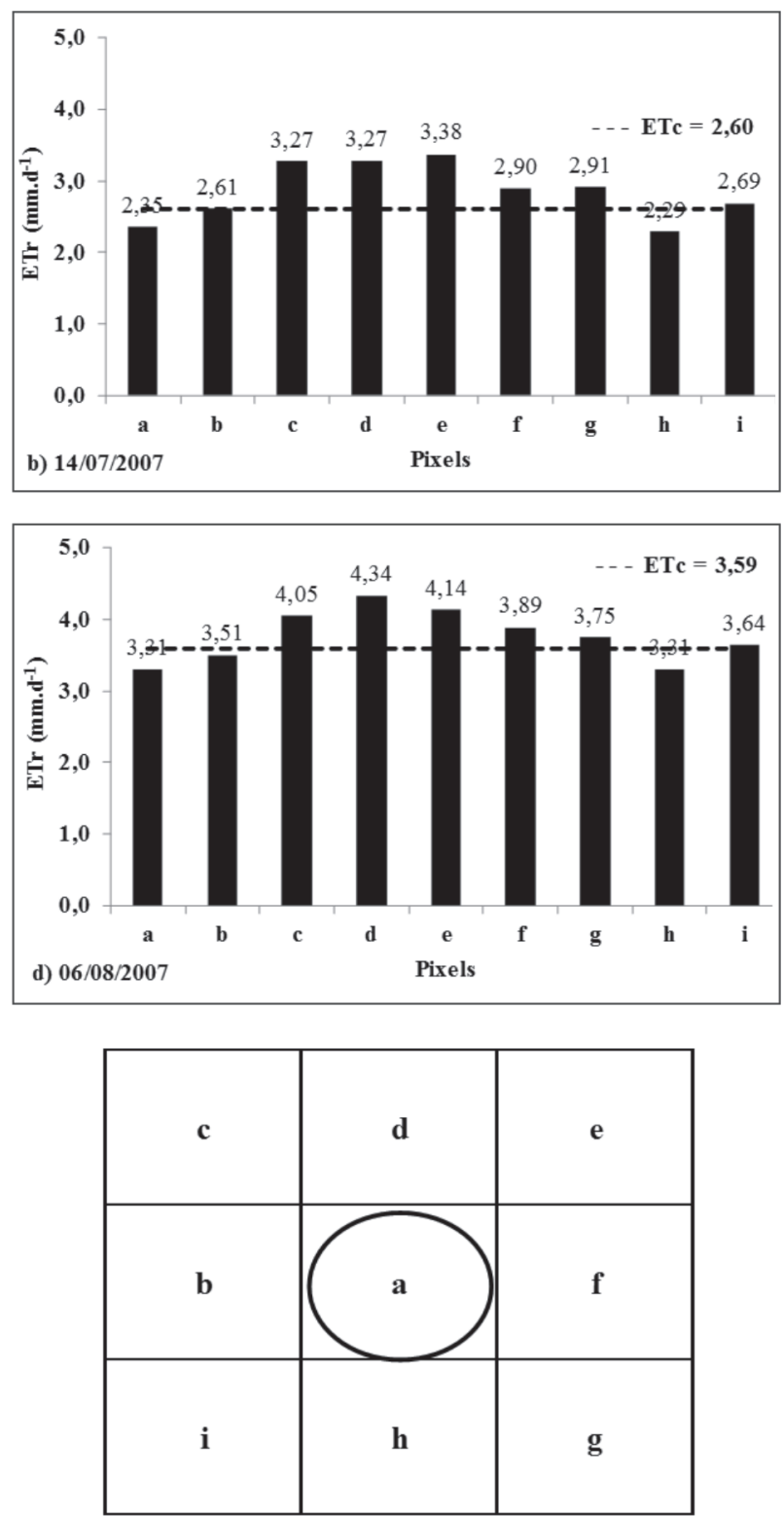

Figura 6. Comparação da evapotranspiração real obtida pelo SEBAL - ETr (mm.dia $\left.{ }^{-1}\right)$, conforme a localização de cada pixel em relação ao pixel referência - "a", e a evapotranspiração da cultura do feijão (ETc), observada na Fazenda Decisão nos dias 10 de julho (a), 14 de julho (b), 23 de julho (c), 06 de agosto (d) e 13 de agosto (e) de 2007. 
as sub-bacias do ribeirão Entre Ribeiros e do rio Preto. Os valores máximos da $\mathrm{ETr}_{\text {díria }}$, obtidos no estudo de Mendonça (2007), foram sempre superiores aos encontrados para as sub-bacias do rio Paracatu. Destaca-se que a cobertura do solo, as datas e o horário de imageamento da superfície pelo satélite foram distintos, em ambos os estudos, e isso pode explicar as diferenças nos resultados.

Além da comparação dos resultados com os de outros estudos, realizou-se a comparação da evapotranspiração real (ETr), obtida pelo SEBAL, com a evapotranspiração da cultura (ETc), verificada para o cultivar de feijão Pérola, na Fazenda Decisão (Figura 6). Vale destacar que, apesar de os termos serem chamados de formas diferentes, a evapotranspiração estimada pelo SEBAL, nesse caso específico, é referente a um pixel que retrata a área de uma cultura com feijão. Na parte inferior da Figura 6, encontra-se o esquema de localização do pixel referência - "a" em relação aos pixels adjacentes - pixels de "b" até "i". As coordenadas geográficas do ponto central do pivô coincidem com o pixel "referência" e serviram para identificar as informações da ETr diária, no pixel "referência" e nos pixels adjacentes, geradas pelo SEBAL.

Nas Figuras 6a e 6c, verifica-se que a maioria dos pixels teve valores da ETr, obtida pelo SEBAL, menores do que a ETc, ou seja, valores menores que 3,23 e 3,12 mm.d. respectivamente. Observa-se que, nas Figuras $6 \mathrm{~b}, 6 \mathrm{~d}$ e 6e, a informação do pixel referência - "a" foi próxima a evapotranspiração da cultura (ETc), determinada para o feijão, na Fazenda Decisão, com erros absolutos (EA) de 0,$25 ; 0,28$; e $0,18 \mathrm{~mm} \cdot \mathrm{dia}^{-1}$, respectivamente (Tabela 2). Observa-se, também, na Tabela 2, que os menores erros relativos médios (ERM) foram de 9,01\% (06/08/2007) e $6,88 \%$ (13/08/2007). Esses resultados foram compatíveis com os encontrados por Oliveira (2012), nos dias 15/08/2010 $(\mathrm{ERM}=10,36 \%)$ e 10/03/2010 (ERM =6,56\%), na bacia do rio Tapacurá, no Estado de Pernambuco.

Tabela 2. Erro Relativo - ER (\%), Erro Absoluto - EA (mm.dia $\left.{ }^{-1}\right)$, Erro Relativo Médio - ERM (\%) e Erro Absoluto Médio - EA $\left(m m \cdot d i a^{-1}\right)$ entre a evapotranspiração real obtida pelo SEBAL - ETr, em cada pixel, e a evapotranspiração da cultura do feijão observada na Fazenda Decisão

\begin{tabular}{|c|c|c|c|c|c|c|c|c|c|c|}
\hline \multirow{2}{*}{ Pixels } & \multicolumn{2}{|c|}{$10 / 07 / 2007$} & \multicolumn{2}{|c|}{$14 / 07 / 2007$} & \multicolumn{2}{|c|}{ 23/07/2007 } & \multicolumn{2}{|c|}{ 06/08/2007 } & \multicolumn{2}{|c|}{$13 / 08 / 2007$} \\
\hline & ER & EA & ER & EA & ER & EA & ER & EA & ER & EA \\
\hline $\mathrm{a}$ & 33,65 & 1,09 & 9,58 & 0,25 & 49,55 & 1,55 & 7,86 & 0,28 & 4,50 & 0,18 \\
\hline $\mathrm{b}$ & 33,78 & 1,09 & 0,31 & 0,01 & 49,81 & 1,55 & 2,37 & 0,09 & 12,21 & 0,48 \\
\hline c & 20,93 & 0,68 & 25,85 & 0,67 & 13,97 & 0,44 & 12,81 & 0,46 & 10,94 & 0,43 \\
\hline d & 9,29 & 0,30 & 25,92 & 0,67 & 1,41 & 0,04 & 20,84 & 0,75 & 22,72 & 0,89 \\
\hline $\mathrm{e}$ & 11,92 & 0,39 & 29,81 & 0,78 & 5,29 & 0,17 & 15,29 & 0,55 & 3,05 & 0,12 \\
\hline f & 21,83 & 0,71 & 11,54 & 0,30 & 29,68 & 0,93 & 8,25 & 0,30 & 1,86 & 0,07 \\
\hline $\mathrm{g}$ & 21,83 & 0,71 & 11,81 & 0,31 & 30,22 & 0,94 & 4,43 & 0,16 & 0,05 & 0,00 \\
\hline h & 29,69 & 0,96 & 11,85 & 0,31 & 51,86 & 1,62 & 7,86 & 0,28 & 0,08 & 0,00 \\
\hline i & 29,88 & 0,97 & 3,42 & 0,09 & 52,08 & 1,63 & 1,42 & 0,05 & 6,49 & 0,25 \\
\hline Médio & 23,64 & 0,76 & 14,45 & 0,38 & 31,54 & 0,98 & 9,01 & 0,32 & 6,88 & 0,27 \\
\hline
\end{tabular}

\section{CONCLUSÕES}

A evapotranspiração real diária e os fluxos instantâneos de calor no solo e sensível, estimados por meio do algoritmo SEBAL, para as sub-bacias do ribeirão Entre Ribeiros e do rio Preto, foram compatíveis com os citados em outras literaturas.

Os resultados da comparação entre a evapotranspiração, obtida pelo SEBAL, e a evapotranspiração da cultura (ETc), verificada para o cultivar de feijão Pérola, demonstraram que esse algoritmo pode ser utilizado como boa opção para determinar, com a utilização de produtos do sensor MODIS, a evapotranspiração diária, nas condições da sub-bacias do ribeirão Entre Ribeiros e do rio Preto.

\section{AGRADECIMENTOS}

À CAPES, pela concessão da bolsa de estudo, e ao $\mathrm{CNPq}$, pela aprovação de auxílio financeiro (Processo $\mathrm{n}^{\circ}$ 471728/2007-1). Ao INMET, pelo fornecimento de dados meteorológicos, e à IRRIGER, pela disponibilização dos dados da evapotranspiração da cultura do feijão.

\section{REFERÊNCIAS}

Allen RG, Trezza R, Tasumi M, Waters R \& Bastiaanssen WGM (2002) SEBAL - Surface Energy Balance Algorithms for Land. Advanced training and user's manual, version 1.0. Kimberly, Department of Water Resources/University of Idaho. 98p.

Andrade RG (2008) Aplicação do algoritmo Sebal na estimativa da evapotranspiração e da biomassa acumulada da cana-de-açúcar. Tese de Doutorado. Universidade Federal de Viçosa, Viçosa. 135p. 
Ayenew T (2003) Evapotranspiration estimation using thematic mapper spectral satellite data in the Ethiopian rift and adjacent highlands. Journal of Hydrology, 279:83-93.

Bastiaanssen WGM, Pelgrum H, Wang J, Ma Y, Moreno JF, Roerink GJ \& Van Der Wal T (1998) A remote sensing surface energy balance algorithm for land (SEBAL) 2. Validation. Journal of Hydrology, 212-213:213-229.

Bastiaanssen WGM (2000) SEBAL - Based sensible and latent heat fluxes in the irrigated Gediz Basin, Turkey. Journal of Hydrology, 229:87-100.

Borges MES (2008) Mapeamento geomorfológico da bacia do rio Preto e sua relação com o uso agrícola. Dissertação de Mestrado. Universidade de Brasília, Brasília. 68p.

Hemakumara HM, Chandrapala L \& Moene AF (2003) Evapotranspiration fluxes over mixed vegetation areas measured from large aperture scintillometer. Agricultural Water Management, 58:109-122.

Latuf MO (2007) Mudanças no uso do solo e comportamento hidrológico nas bacias do rio Preto e ribeirão Entre Ribeiros. Dissertação de Mestrado. Universidade Federal de Viçosa, Viçosa. 103 p.

Lima EP (2010) Estimativa da evapotranspiração e do balanço hídrico a partir de imagens de satélite de duas sub-bacias do Paracatu. Tese de Doutorado. Universidade Federal de Viçosa, Viçosa. 161p.

Lima EP, Sediyama GC, Silva BB, Gleriani JM \& Soares VP (2012) Seasonality of net radiation in two sub-basins of Paracatu by the use of MODIS sensor products. Engenharia Agrícola, 32:1184-1196.

Medina JL, Camacho E, Reca J, López R \& Roldán J (1998) Determination and analysis of regional evapotranspiration in Southern Spain based on remote sensing and GIS. Physics and Chemistry of the Earth, 23:427-432.
Mendonça JC (2007) Estimativa da evapotranspiração regional utilizando imagens digitais orbitais na região Norte Fluminense, RJ. Tese de Doutorado. Universidade Estadual do Norte Fluminense, Campos dos Goytacazes. 145p.

Moreira MC (2006) Gestão de recursos hídricos: sistema integrado para otimização da outorga de uso da água. Dissertação de Mestrado. Universidade Federal de Viçosa, Viçosa. 94p.

Nicácio RM (2008) Evapotranspiração real e umidade do solo usando dados de sensores orbitais e a metodologia SEBAL na bacia do rio São Francisco. Tese de Doutorado. Universidade Federal do Rio de Janeiro, Rio de Janeiro. 320p.

Oliveira LMM (2012) Estimativa da evapotranspiração real por sensoriamento remoto na bacia do rio Tapacurá-PE. Tese de Doutorado. Universidade Federal de Pernambuco, Recife. 136p.

Rollenbeck R \& Anhuf D (2007) Characteristics of the water and energy balance in an Amazonian lowland rainforest in Venezuela and the impact of the ENSO-cycle. Journal of Hydrology, 337:377-390

Ruhoff AL (2011) Sensoriamento remoto aplicado à estimativa da evapotranspiração em biomas tropicais. Tese de Doutorado. Universidade Federal do Rio Grande do Sul, Porto Alegre. 162p.

Silva BB \& Bezerra MVC (2006) Determinação dos fluxos de calor sensível e latente na superfície utilizando imagens TM Landsat 5. Revista Brasileira de Agrometeorologia, 14:174-186.

Timmermans WJ \& Meijerink AMJ (1999) Remotely sensed actual evapotranspiration: implications for groundwater management in Botswana. International Journal of Applied Earth Observation and Geoinformation, 1:222-233. 